\title{
SOFRIMENTO ÉTICO-POLÍTICO DE INDÍGENAS SATERÉ- MAUÉ E HIXCARIANA QUE MIGRAM DE SUAS ALDEIAS
}

ETHICAL-POLITICAL SUFFERING OF INDIGENOUS SATERÉ-MAUÉ AND HIXCARIANA PEOPLES WHO MIGRATE FROM THEIR ORIGINAL LAND

EL SUFRIMIENTO ÉTICO-POLÍTICO DE LOS INDÍGENAS SATERÉ-MAUÉ E HIXCARIANA QUE MIGRAN DESDE SUS ALDEAS

Renan Albuquerque

Flávia R. Busarello**

\begin{abstract}
RESUMO
Este artigo teve como objetivo ponderar acerca de sofrimentos de grupos que se veem forçados a migrar para espaços urbanos na Amazônia, rompendo relações com a terra. Foram utilizadas categorias analíticas de dois grupos de pesquisa de universidades brasileiras e apresentados relatos de sofrimento psíquico de indígenas das etnias sateré-maué e hixcariana, ambas no Estado do Amazonas, após a migração para a cidade. A metodologia de coleta foi a etnografia, e a análise foi feita sob categorias da Psicologia sócio-histórica. Resultados sugerem que a desigualdade social vivida pelos povos indígenas atravessa os sofrimentos vividos na urbe, caracterizando-se por ser um sofrimento ético-político. A concepção de saúde e a categoria de comum se mostraram, neste artigo, como formas de potência para esses povos viverem em contexto urbano.
\end{abstract}

Palavras-chave: Sofrimento ético-político. Povos indígenas. Psicologia sócio-histórica.

\begin{abstract}
This article aimed at bringing into consideration the suffering of groups that are forced to migrate to urban spaces in the Amazon area, breaking up their relations with the land. We have used analytical categories of two research groups from Brazilian universities and presented reports of psychological distress experienced by Sateré-Maué and Hixcariana indigenous people, in
\end{abstract}

\footnotetext{
Doutor em Sociedade e Cultura na Amazônia pela Universidade Federal do Amazonas (UFAM); desenvolve estágio de pósdoutorado em Psicologia social pela Pontifícia Universidade Católica de São Paulo (PUC São Paulo), realizou estágio de pósdoutorado em Antropologia na PUC São Paulo, com intercâmbio na Universidade Nacional da Colômbia (Unal); coordenador do Programa de Pós-Graduação em Ciências da Comunicação da UFAM; lidera o Núcleo de Estudos e Pesquisas em Ambientes Amazônicos (Nepam/UFAM).

** Doutoranda no Programa de Psicologia Social da PUC São Paulo, participa do Núcleo de Pesquisa Dialética Exclusão/Inclusão Social (Nexin), mestra em Psicologia Social pela PUC São Paulo, graduada em História e Psicologia pela Fundação Universidade Regional de Blumenau (FURB).
} 
the Amazonas State, after migrating to the city boundaries. Ethnography was applied as the methodology of collection and the analysis was carried out under categories of sociohistorical Psychology. Results suggest that the social inequality experienced by indigenous peoples goes through the sufferings experienced in the city, being characterized as an ethical-political suffering. The concept of health and the category of common, on this paper, proved to be forms of power for these peoples to live in an urban context.

Keywords: Ethical-political suffering. Indigenous peoples. Sociohistorical Psychology.

\section{RESUMEN}

Este artículo tuvo como objetivo reflexionar sobre el sufrimiento de los grupos que se ven obligados a migrar a espacios urbanos en la Amazonía, rompiendo relaciones con la tierra. Se utilizaron categorías analíticas de dos grupos de investigación de universidades brasileñas y se presentaron informes de angustia psicológica de las etnias indígenas Sateré-Maué e Hixcariana, en el Estado de Amazonas, después de la migración a la ciudad. La metodología de recolección fue la etnografía y el análisis se realizó bajo categorías de Psicología sociohistórica. Los resultados sugieren que la desigualdad social experimentada por los pueblos indígenas atraviesa los sufrimientos experimentados en la ciudad, caracterizándose como un sufrimiento ético-político. El concepto de salud y la categoría de común, en este artículo, demostraron ser formas de poder para que estos pueblos vivan en un contexto urbano.

Palabras clave: Sufrimiento ético-político. Pueblos indígenas. Psicología sociohistórica.

\section{CONTEXTUALIZAÇÃO DO PROBLEMA E NOTAS INFERENCIAIS}

onforme o Censo de 2010, no Brasil, há 818 mil pessoas que se declaram
indígenas. Destas, 502.783 vivem em áreas rurais, e 315.180 , em áreas
urbanas. A relação entre Estado brasileiro e povos originários, porém,
foi marcada por etnocídios, violações a direitos e assimilação sociocultural, do
qual o Estatuto do Índio, de 1973 (Lei no $6.001 / 1973$ ), é um exemplo claro,
porque tinha objetivo de integrá-los, progressiva e forçadamente, à comunhão
nacional. A partir de 1988, com a última Constituição Brasileira promulgada, o
Estado reordenou a relação com ameríndios e comprometeu-se a "[reconhecer]
organização social, costumes, línguas, crenças, tradiçôes e direitos dos originários
sobre terras que tradicionalmente ocupam, competindo à União demarcá-las, 
proteger e fazer respeitar os seus bens" (artigo 231). A partir da Carta Federal, povos tradicionais passam a ter respaldo jurídico para reproduzir processos e estatutos socioculturais. ${ }^{1}$ Um dos tópicos de destaque, presente no artigo $231 \mathrm{da}$ Constituição, é a proteção ao direito de indígenas às terras.

O Estado reconhece, assim, que a terra não representa somente um espaço habitável, mas dominial e simbólico, de produção do ethos nativo, de modos de vida e morte. Assim, constitui-se em um território concreto onde indivíduos estabelecem relações e vínculos afetivos, destaque-se, destoantes da maneira como a terra é compreendida hegemonicamente na sociedade brasileira/ocidental: uma propriedade juridicamente delimitada. Porém terras indígenas (TI) continuam sendo invadidas e roubadas, gerando processos de migração.

Quando destacamos que o território tem característica de afetividade e ancestralidade, é compreendido que a ligação com esses locais é histórica bem como o trânsito feito a partir deles. Ao tratar a migração, vale frisar, que o fazemos de modo conceitual (Cedeplar, 1977; Martine, 1987). Estamos entrando em um campo epistemológico delicado para o entendimento de processos de idas e vindas de povos indígenas, sobretudo no que tange à concepção primordial de fluxos e trânsitos de pessoas de etnias amazônicas, tanto que sociedades originárias das terras baixas da América do Sul entendem e determinam domínios territoriais e ancestralidades da terra com base em imemorialidades cosmológicas, que compreendem crenças, atitudes, valores e ideologias. Desta feita, ao se tentar circundar significados do conceito de migração, tem-se que ele foi construído sob égide e viés branco, eurocêntrico e hegemônico.

A migração de indígenas para a cidade não é um ato conjuntivo de uma mudança de ares ou ambientes. Trata-se de uma caminhada dentro de territórios primordiais os quais já detinham, exploravam e onde nele se moviam e moldavam às suas necessidades. Em que pese centrar o estudo com base no viés dos SateréMaué e dos Hixcariana (ambas nações indígenas fixadas em TI do Amazonas, mas que realizaram igualmente descimentos ao longo do rio Amazonas/Solimões nos séculos XVII, XVIII, XIX e XX), é fato que inúmeras etnias por igual se desdobraram e se desdobram atualmente em suas concepçóes de território e transitam para além do que é reconhecido burocraticamente como terra indígena.

A partir disso, como aponta Klein (2000, p. 13), "A migração não começa até que pessoas descobrem que não conseguirão sobreviver com seus meios tradicionais em suas comunidades de origem". E, com mudanças implantadas pelo capitalismo e a consequente urbanização, resta ao indígena migrar para polos urbanos avizinhados a suas terras, em busca de trabalho, estudo e saúde. No

1 No entanto é importante salientar que o Estatuto do Índio, apesar de estar em flagrante contradição com a Constituição Federal, ainda se encontra juridicamente em vigor. 
entanto a movimentação para cidades ocasiona sofrimentos e vivências diferentes da TI. O objetivo foi ponderar acerca de sofrimentos de grupos que se veem forçados a migrar para espaços urbanos na Amazônia, rompendo relações com a terra. Importante salientar que "falar em migração implica automaticamente em falar em cultura” (Sarriera, Pizzinato, \& Meneses, 2005, p. 6). Portanto, ao tratar a migração, pressupóe-se a perspectiva da interculturalidade em virtude do "contato entre pessoas de culturas distintas, de universos simbólicos compartilhados, assinalar uma dimensão de interação" (Demorgon, 1999 apud Dantas, 2012, p. 16).

Nossa ponderação foi interdisciplinar e partiu de categorias analíticas do Núcleo de Pesquisa da Dialética Exclusão-Inclusão Social (Nexin) e da etnografia contextual realizada pelo Núcleo deEstudose Pesquisas em Ambientes Amazônicos (Nepam), da Universidade Federal do Amazonas (UFAM). O primeiro GP é da área da Psicologia social e outro da Antropologia/Sociologia. Reflexões do Nexin indicam conceitos de afeto e comum (Spinoza, 2014) para análises de desigualdade social, entendendo que "A segregação se configura espacialmente onde as relações caminham no sentido de diminuir formas coletivas de luta pela libertação de cada um e pela igualdade de todos" (Sawaia, 1995, p. 24). Em outras palavras, a migração favorece a quebra do comum que os caracteriza. Dessa forma, defendemos ser a missão de ambas as ciências a construção do comum (Spinoza, 2014). Destaque-se que o comum é sentimento, pensamento e ação. O conceito, na concepção spinoziana, não é a mera união instrumental para realizar ação comum. É felicidade de estar e fazer juntos o "útil comum” (Spinoza, 2014).

\section{O BOM ENCONTRO TEÓRICO}

Da parte do Nepam, o viés da Antropologia pós-estruturalista foi enfocado. Embora a desconstrução proposta por Derrida (2004) ao método da estrutura aprofundado seja uma sistemática de análise crítico-literária, de identificação e descrição de significados em narrativas e textos, ela não é analisada em contexto literoficcional, mas dentro de eixos psicológicos. E assim nos encaminhamos, sob o ponto de vista da construção de indivíduos, coletivos e memórias compartilhadas dos comuns Sateré-Maué e Hixcariana. Foi nesse desejo que

Residiu nossa aventura comunitarista: a energia fundadora do laço social está no desejo de aumentar o conatus ${ }^{2}$, a qual é capaz de explicar porque nenhum momento da história conseguiu anular a capacidade humana de criação de caminhos de fuga (Sawaia, 2008, p. 153). 
Muito embora possa inibi-la a ponto de se ter a morte em vida, enredando pessoas na teia da servidão e do sofrimento, que muitas vezes é confundido com transtorno mental (de viés hospitalocêntrico), por levar o indígena a comportamentos não esperados pela ordem social, a energia fundadora é essencial para a concepção da existência. Essa é aumentada e diminuída de acordo com afecçôes dos encontros cotidianos. Quando partilhamos bons encontros, que são os que aumentam essa potência, sentimos alegria e outras emoções dela derivadas. Ao contrário, quando partilhamos maus encontros, despotencializadores, somos afetados por emoções tristes. Por isso, a ética está nos afetos (Spinoza, 2013).

Procuramos salientar o debate sobre essa questão na Antropologia, entre a perspectiva naturalizante e a culturalista, e no contexto do sofrimento psíquico como patologia psicossocial, resultante das mazelas da vida, inclusive de ordem genética. Nesse particular, Rutter e Sroufe (2000), e Cicchetti e Cohen (2006) consideram que esses sofrimentos observados em indígenas tendem a ser decorrentes de inter-relações e contingências múltiplas, associadas a características específicas pessoais (fatores biológicos, genéticos e psicológicos), ambientais (cuidado parental, relacionamentos interpessoais, exposição a eventos estressores) e contingências sociais (rede de apoio social, vizinhança, nível socioeconômico), dentro de uma cadeia de fatores que se cruzam e conectam por variantes.

De igual monta, o sofrimento psíquico de indígenas é decorrente menos de deficiências orgânicas, físicas e psíquicas do que de rejeições manifestas ao ambiente e ao conjunto de arbitrariedades que os envolve. É um tanto daquilo que Clastres (2002) observa, partindo de perspectiva sociológica, acerca da rejeição do Estado por sociedades tradicionais não como algo que rechaçam por incompreensão funcional, mas a que se opõem porque reconhecem mecanismos de não alinhamento a pensamentos dominantes. Ele defende que o sofrimento psíquico não se reduz a experiências negativas, mas sim indica múltiplas interseçōes expostas no processo de desfiliação de mundo das etnias por causa de dinâmicas enfrentadas na urbe, as quais são impulsionadas por situações-limites.

Analisar o sofrimento psíquico entre grupos indígenas migrantes, ampliado pelo conceito de sofrimento ético-político, foi a pretensão no texto, sendo que a intenção da reflexão, na conjuntura, passou ao largo da ação de rotular com a etiqueta de "transtornos mentais" fenômenos que saem do padrão de vida orientado pela sociedade não indígena. $\mathrm{O}$ suposto se dirige a questionamentos sobre:

a) o quanto sociedades não indígenas se esforçam por negar alteridade a grupos étnicos; 
b) o que há de implicações socioculturais no sofrimento psíquico;

c) até que ponto desdobramentos decorrem do modo de vida das cidades no corpo e na mente de indígenas; e

d) em que medida a desigualdade social, subjacente a estados de descaracterização étnica (migração forçada), explica quadros de sofrimento em dimensões ético-políticas.

O estudo buscou considerar complexidades socioculturais. Interpretações de experiências foram tomadas como exercícios de alteridade, porque, na lógica dos povos originários, por exemplo, o que o saber psicológico da civilização ocidental entende como "sofrimento psíquico" pode ser denominado de judiação, dismintidura, rasgadura, feitiçaria, rebeliāo, assombramento, calor de sol, roubo de sombra, mal de beberagem ou de comidaria (Rodrigues, Paiva, \& Catalão Júnior, 2012). Sobre o jovem que se rebela, a pessoa adulta que faz atos rejeitáveis na comunidade e o ancião ou anciã que se suicida, todos, na visão indígena, podem estar em fase de desregramento do espírito humano. Em parte dos casos, males são notados e, em seguida, se dispersam, permitindo que sigam com suas sanidades, sem categorizações de patologias. Para indivíduos sateré-maués e hixcarianas, é provável que inexista a episteme referente à compreensão de patologias psíquicas como males, pois sua cosmologia entende como não referenciada a diferença entre corpo e alma, entre físico e espiritual, posta a característica tênue dessas divisões e a não dualidade nem para sociedades brancas. A cosmologia de cada povo originário é essencial para o entendimento do sofrimento no contexto migracional aldeia-cidade, pois é esse saber que compõe a afetividade desses indivíduos e sua relação com o mundo, o que demonstra limitações de conceitos desenvolvidos pela sociedade branca e eurocêntrica.

Diferente do que ocorre na cultura ocidental, higienista e hospitalocêntrica, esquemas generalizantes ou universalizantes reforçam a cisão entre aquilo que é próprio do conhecimento simbólico (o medicamento ancestral ministrado para dores da alma) e aquilo que é inerente a sociedades não indígenas e principalmente urbanas (o medicamento sintético e direcionado a órgãos do corpo) (Kirmayer, 2009). Sociedades indígenas são estranhas a populações urbanas ocidentais visto que a relação de nativos com a vida e seus significados é intermediada pelo não dito, pelo subjetivo, sem rupturas entre mundos físico e metafísico. "O mundo deles (brancos) é quadrado, eles moram em casas que parecem caixas, trabalham dentro de outras caixas, e para irem de uma caixa a outra, entram em caixas que andam. Eles veem tudo separado porque são o povo das caixas" (Kaingang apud José, 2015). 
O encontro teórico entre o Nexin e Nepam possibilitou ir além da concepção de sofrimento psíquico, ampliando-o para uma visão ético-política, de forma que a exclusão de benefícios públicos se torna categoria de saúde, como também a cosmologia é inclusa e encarnada nesses indivíduos. Portanto, para enfocar o sofrimento como sofrimento ético-político, foi preciso considerar que o modelo biomédico usado para tais análises e a consequente caracterização de perturbações como patologias tratáveis por viés sintético não atende à totalidade conceitual de saberes e fazeres de povos originários, a qual integra normalizações orientadas por cosmologias. Foi preciso entender que segregação, exclusão de benefícios públicos e ataques à cosmovisão de povos autóctones (ou seja, que vivem na mesma macrorregião geográfica historicamente) tornam-se categorias de saúde mental. Atualmente, por exemplo, indígenas encontram-se em centros urbanos de atendimento. Porém há singularidades no modo de afetação de indígenas. Estas os impactam segundo suas ancestralidades. Comte-Sponville (2001) defende a despatologização de sofrimentos correlatos a pressões socioeconômicas e políticas, questionando definiçôes de felicidade e amor.

Parcela da ciência psi contemporânea concorda que processos de sofrimento resultam da complexa correlação de circunstâncias sociais e pessoais, em que contingências diversas ocorrem em conformidade a manifestações biológicas. Mas a visão está longe de ser consensual. Sofrimentos de indígenas na cidade se agravam por características que marcam o capitalismo, como consumismo, degradação ambiental, individualismo e intolerância à diversidade. A sociedade capitalista cria dificuldades quando fomenta a cultura do imediatismo, do desejo de consumo e a rejeição ao que não pertence ao Ocidente. Em alguma medida, em sociedades urbanas amazônicas, vem ocorrendo o que Botton (2005) afirma ser um problema universal: a destruição da capacidade de interesse das pessoas em valores globais, como liberdade, ética e igualdade. Comunidades existentes na Amazônia guardam alta capacidade de forçar apagamentos estruturais (desfiliação) de povos originários mediante essas balizas, com base em relações em que tradições são rejeitadas para o surgimento de efemeridades desimportantes (Santos, 2013). Ao não se alinharem a vicissitudes urbanas, a consequência foi a abertura de precedentes para quadros de sofrimento. Comportamentos que não seguem padrões preestabelecidos funcionam para fomentar humilhações.

Dentro do contexto presente do espaço amazônico, o reforço à segregação vem sendo repetido tal e qual uma mutação, uma modificação caótica de sentidos, que marca a floresta, as águas e as cidades do bioma, de modo que a identidade de povos originários da hileia tropical brasileira vem sendo baseada em coisas que não têm regência na natureza e na vida, formando fatores de desencadeamento e sofrimentos. 


\section{REFLEXÕES A PARTIR DE ANTROPOLOGIA E PSICOLOGIA SOCIAL}

Devido à dificuldade de adaptação por conta de processos migratórios sem planejamento, apoio familiar, social e estatal, indígenas que se submetem à mudança da aldeia para a cidade tendem a fragilizar seu cuidado parental e ter as condiçôes nutricionais e de habitação pioradas em termos gerais (Costello, Compton, Keeler, \& Angold, 2003). Albuquerque, Ferreira, Schweickardt, e Cordeiro (2016), e Garnelo, Diniz, Sampaio, Silva, (2010) sugerem que existam correlações entre fluxo migracional e saúde mental, principalmente no que tange a aspectos socioculturais de enfermidades. $\mathrm{O}$ efeito tende a ser notado conforme o cotidiano dos tradicionais é mediado mais por relaçôes transitórias (projetadas pela funcionalidade de ambientes urbanos) que por identidades construídas historicamente (Garnelo \& Wright, 2001; Albuquerque et al., 2016).

No caso dos Sateré-Maué e Hixcariana, as migrações iniciaram-se em 1967, com a criação da Zona Franca de Manaus, motivadas, segundo o Diagnóstico Sócio Demográfico Participativo da População Sateré-Maué, pela busca por trabalho assalariado (Teixeira, Mainbourg, \& Brasil, 2009). Engendrava-se também a saída das terras aldeadas devido à necessidade de reconhecimento social ou em razão da fuga da tutela do Estado. Ambas incidiam como razões explicativas para o fluxo migracional. Nesse ponto, cabe destacar o que acreditamos ser a ideia de migração para sociedades de terras baixas da América do Sul. E ainda, para refletir sobre processos de sofrimento psíquico, notamos a reconfiguração da condição espaçotemporal de migrantes indígenas do Baixo Amazonas bem como a vivência em uma sociedade mercadocêntrica, mediada por traços discriminatórios. Mudanças de sociocultura e modos de vida da terra indígena para a cidade, considerando a historicidade e a violências vivenciadas no contexto urbano, implicam sofrimentos. E relações de poder e expropriação, bem como relações políticas e inclusões forçadas e assistencialistas, são interveniências negativas. O sofrimento precisa, portanto, ser analisado pela mediação da dialética exclusão/inclusão.

A dialética inclusão/exclusão gesta subjetividades específicas que vão desde o sentir-se incluído até o sentir-se discriminado ou revoltado. Essas subjetividades não podem ser explicadas unicamente pela determinação econômica, elas determinam e são determinadas por formas diferenciadas de legitimação social e individual, e manifestam-se no cotidiano como identidade, sociabilidade, afetividade consciência e inconsciência (Sawaia, 2001, p. 9).

A possibilidade de enriquecimento cultural mediante a troca de experiências deveria ser um bom encontro (Spinoza, 2013). Todavia sociedades indígenas 
convivem com processos de inclusão perversa (Sawaia, 2001). A crença em narrativas históricas e no papel social que a cosmologia indígena tem é interpretada como frivolidade ou leviandade de velhos, sobretudo conforme percepções de migrantes indígenas que na cidade podem vivenciar universos desconhecidos (Rodrigues, Paiva, \& Catalão Júnior, 2012). Esse processo de inclusão pela exclusão social gera "o sofrimento [que] é a dor mediada pelas injustiças sociais. É o sofrimento de estar [a pessoa] submetida à fome e à opressão, e pode não ser sentido como dor por todos" (Sawaia, 2001, p. 102), mas pelos que sofrem a inclusão perversa. Considerar, portanto, afetos e emoções no estudo da inclusão “é [. . . ] refletir sobre o 'cuidado' que o Estado tem com seus cidadãos. Eles são indicadores do (des)compromisso com o sofrimento humano, tanto por parte do aparelho estatal quanto da sociedade civil e do próprio indivíduo" (Sawaia, 2001, p. 99).

Ao analisar pessoas em situação de rua, é preciso considerar que "o sofrimento dos que vivem a inclusão perversa revela o processo de exclusão afetando o corpo e a alma, com muito sofrimento, sendo o maior deles o descrédito social, que os atormenta mais que a fome" (Sawaia, 1999, p. 115), sendo uma das suas consequências o sentimento de impotência, humilhação e desamparo. A partir disso: o sofrimento ético-político "retrata a vivência cotidiana das questôes sociais dominantes em cada época histórica, especialmente a dor que surge da situação social de ser tratado como inferior, subalterno, sem valor, apêndice inútil da sociedade" (Sawaia, 2001, p. 104).

O sofrimento de étnicos assola corpos e mentes e desregra vidas de modo constitutivo. Tanto porque é um sofrimento ético-político, ocasionado conforme as pessoas sateré-maués e hixcarianas migram para a cidade e vivenciam o polo urbano e a exclusão/inclusão social por meio do cotidiano citadino, notado a partir de encontros que vivenciam e com a ideologia ocidental. Em virtude disso, nativos que não "chegam lá" não vencem segundo padrões capitalistas, são derrotados, incompetentes perante os outros e, em razão de sua incompetência, não conseguem se adequar no novo mundo (Santos \& Nunes, 2003). E com o passar do tempo, tanto ficar na cidade como voltar para a TI gera sofrimento. $\mathrm{Na}$ cidade, por conta da exclusão/inclusão social; na TI, pelo regresso furtivo, a representar derrota.

A preocupação com a coletividade, a cosmologia, a contemplação crítica do mundo, que fizeram indígenas superarem obstáculos ao longo da história, são observadas como construçóes da realidade, compreendidas tal e qual atividades de pessoas obtusas, pautadas no ingênuo idealismo silvícola. Construções psicossociais tradicionais, nesse sentido, têm sido tratadas como crenças insignificantes ou banalidades sem implicações práticas para a vida: sejam em 
esferas sociais, políticas ou econômicas. $\mathrm{O}$ imaginário indígena é discriminado e sobreposto pelo conhecimento cientificista do branco.

O conceito de sofrimento ético-político tem por base a filosofia spinoziana, de tendência ontológica, que retira indivíduos da condição de máquina e os reposiciona como seres de potência. Segundo o autor, "O corpo humano pode ser afetado de muitas maneiras, pelas quais sua potência de agir é aumentada ou diminuída, enquanto outras tantas não tornam sua potência de agir nem maior nem menor" (Spinoza, 2013). Esse corpo possui conatus, que é a potencialidade, e responde a afetações de encontros, que podem ser bons ou não.

A potência de conservação é também poder de ser afetado, o que significa que ela, apesar de ser irreprimível, varia de intensidade, a depender das intersubjetividades que me constituem, isto é, das afecções (affections) que meu corpo e minha mente sofrem nos bons ou maus encontros do passado, do presente e do futuro (Sawaia, 2009, p. 366).

Afetos são radares indicativos de formas de engendramentos do corpo e mente, além de funcionarem como motivadores de ação (Sawaia \& Silva, 2015). São gerados e reproduzidos em encontros com o outro. Encontros são bons quando aumentam a potência de vida; são maus quando atrelam a existência à servidão. Acerca da abordagem, relacionando-a ante o cenário dos indígenas sateré-maués e hixcarianas que vivenciam na cidade a dialética exclusão/inclusão social, temos que, devido à imersão em um sistema que privilegia produção e acumulação em detrimento da dignidade e autonomia intelectual de diferentes povos, controvérsias e fragmentações são observadas a partir do relacionamento dos nativos com as coisas dos brancos (Kelly, 2005). Os afetos dos povos indígenas, porquanto, tendem a deslocar-se negativamente diante de projeçôes de vida em espaços urbanos.

Exemplificando o disposto, notemos algumas situações vividas na urbe:

Índia Sateré-Mawé, atendida pelo CAPS/PIN, oriunda de Araticum (comunidade da TI Andirá-Marau), um dos polos étnicos do Município de Barreirinha/AM, levava vida ordinária até quando a família the organizou casório orientado, como de costume, com membro da comunidade. Antes de completar 18 anos não tinha engravidado, o que era considerado atraso em padrôes indígenas e por isso uniu-se a um jovem. Com o passar do tempo, ela e o marido decidiram vir para a cidade, fugindo de críticas sobre a infertilidade. Ao se instalarem no reduto urbano de Barreirinha, as cobranças continuaram. Desta vez, era o companheiro que pedia uma criança o quanto antes porque precisava retornar à aldeia e compartilhar a notícia com os homens Sateré-Mawé, esvaindo de modo positivo a conturbada retirada para a cidade. Mas, sem mudanças, tempos depois, a separaçăo do casal ocorreu devido seguidas tentativas infrutíferas de gravidez. $\mathrm{O}$ homem retornou à aldeia de imediato e não houve mais notícias dele. A mulher, ao permanecer na cidade, desenvolveu traços esquizofrênicos, marcados por comportamentos bizarros (Rodrigues et al., 2012, pp. 101-102). 
Um controverso caso a se refletir acerca do sofrimento mental indígena diz respeito a uma pré-adolescente de 12 anos, que havia presenciado o assassinato do pai em uma aldeia Sateré-Mawé [. . .]. Uma hipótese foi baseada na interpretação dos sonhos que a jovem índia disse ter tido, os quais eram situados na sua terra de nascimento, a TI Andirá-Marau. Identificou-se que o falecido insistia, em sonho, para que ela voltasse a morar junto dele, cujo corpo estava enterrado na terra indígena. Na TI, a jovem deveria se submeter à influência xamânica de preceptores Sateré-Mawé para que eles expurgassem dela os espíritos maus. $\mathrm{O}$ pai teria dito ainda para a menina que havia sido assassinado por vingança e que ela devia fazer trabalhos de pajelança com os iniciados espirituais da aldeia de origem, caso quisesse continuar viva. Para isso, ela deveria trabalhar para devolver ao espírito do falecido o sossego (Rodrigues et al., 2012, pp. 106-107).

É possível supor até que ponto o vínculo com a TI permanece, independente do motivo da migração. $\mathrm{O}$ vínculo e a cosmovisão alterados concorrem para afetar Sateré-Maué e Hixcariana tanto com bons quanto com maus encontros. Muitos casos de sofrimento, inclusive, podem ser intensificados com a ida para a cidade, dado que, na urbe, há ampla individualização e desamparo. Dado exemplo é verificado na primeira citação, em que a pessoa vivencia emoções de medo na TI que se intensificam na cidade e a lançam a situações críticas de insegurança. As incidências suprimem suas historicidades e cosmovisōes.

São corporeidades e mentalidades constantes no bojo das afetaçóes dadas no espaço urbano, as quais se mostram para que compreendamos paralelos do sofrimento, visto que a TI é lugar de encontros potencializadores e a cidade se diferencia pela existência da dialética exclusão/inclusão social. Conhecimentos indígenas, sejam cosmológicos, parentais ou miméticos de contexto ancestral, como mediadores e fomentadores de natividades, podem funcionar inversamente como componentes que dificultam a vida urbana. É a própria ancestralidade e o espaço étnico compartilhado que fortalecem esses indivíduos no contexto urbano. Mas laços comunais concorrem para promulgar maus encontros.

Ansiedade, vergonha, angústia e humilhação passam a ser afetos que caracterizam a vida indígena no espaço urbano. Os Sateré-Maué e Hixcariana, na cidade, vivenciam novas formas de interação sociocultural e econômica, propulsoras do esfacelamento de sentimentos de comunalidade. $\mathrm{Na}$ cidade, a ideologia dominante é a do capital, da cientificidade higienizadora e da branquitude, o que pode gerar sofrimentos a partir da ideia de "ser diferente" Ademais, dinâmicas ambientais e processos que norteiam vidas em aldeias fortalecem a relação com a região onde habitam, sendo que xamãs (pajés) e tuxauas (líderes políticos) podem orientar essa modificação, servir de guias e conselheiros. Eles guardam a capacidade de compreender, por exemplo, extensas faixas de terra no bioma como áreas comuns e próprias para a realização de 
trabalhos espirituais e reuniōes de partilha, onde podem ser facilitadas as tomadas de decisão na economia e na política, além de perceberem o rearranjo de modelos sociais e o reordenamento dos recursos da biodiversidade de maneira integrada, sem subdivisões ocultadoras do real.

A função central de especialistas [xamãs e tuxauas] é de manter um diálogo constante com seres humanos invisíveis, considerando o cosmo e o meio ambiente equilibrado, com condiçōes habitáveis a seres humanos e animais, vegetais e minerais. $\mathrm{O}$ esquema de comunicação entre wai-mahsã e humanos se dá através de pessoas preparadas, nos momentos específicos e com conhecimentos específicos. As categorias de yai, kumu ou baya [categorias de xamãs] ficaram escassas e a especialidade de yai [xamã de alta hierarquia que repassa seus conhecimentos de cura] praticamente foi extinta em todo o noroeste amazônico brasileiro. Os kumuã [plural de kumu] existem, mas são poucos; eles tiveram sua formação antes do alcance em suas comunidades pelos missionários. A maioria, porém, foi atingida em algum momento de sua preparação, sendo forçada a frequentar a escola aí instalada, como foi o caso do meu pai Ovídio Lemos Barreto, e meus tios Luciano Barreto e Tarcísio Barreto. Eles são os últimos kumuã Tukano do "sib" huremeri saroró yupuri bubera-porã, moradores do rio Tiquié, na Comunidade de São Domingos Sávio, em São Gabriel da Cachoeira (Amazonas). Pela falta de yai, os poucos kumuã que restaram se veem forçados a cumprir o papel daqueles, efetuando assim uma dupla função no sistema de comunicação extrahumano e de cura, diagnosticando doenças e realizando bahsesse (benzimentos). Como não há atualmente a continuidade na formação de novos especialistas kumuãa, podemos dizer que, a exemplo do que aconteceu com os yai, os kumuã estão fadados a desaparecer (Barreto, 2013).

Os trechos, que tratam de intersecções entre o status da pessoa xamânica, a formação dela e a sua saúde mental para a execução de trabalhos de cura e terapêutica tradicional, são interessantes pelos simbolismos neles contidos. Esses se mostram como códigos a projetarem entendimentos em razão de leituras relacionais do autor (Barreto, 2013) e seus modos de vida. Partindo da premissa:

a) inferimos que João Paulo Barreto Tukano constrói ideias sobre sua etnia e as apresenta na relação entre dois conhecimentos distintos, o do branco e o do índio;

b) que o texto tenta decodificar mensagens complexas e de duplo sentido, um terreno e outro cósmico.

Barreto (2013) destaca a permanência de práticas ancestrais xamânicas por meio dos mesmos afetos tratados e dentro de uma paradigmática situação de deslocamento temporal. Investigar a ideia do "comum" para um ameríndio amazônico não é um ato de designar quem é quem. Tem a ver com a maneira que o coletivo concebe formas de expressão e as remete a afirmativas parentais e 
clânicas. Trata-se menos, portanto, de ponderar sobre quem é ou não essa pessoa nativa migrante a partir de um discurso, mas sim contextualizá-la. Interpretando as consideraçôes, aparentemente antagônicas, bem como as possibilidades de compreensão de fenômenos psicossociais mediante a "diplomacia espiritual xamanística" (Albuquerque \& Junqueira, 2017, p. 128), temos que a correlação entre ambiente externo e sofrimentos se mantém persistente e pode ser validada por agentes da pajelança.

Aqui repousa a preocupação deste texto: não reduzir aspectos da saúde apenas a sujeitos em si mesmos, ao seu funcionamento psíquico ou biológico, mas contemplar relacionamentos com o mundo externo (social) e, no caso de nossas inferências, ao mundo urbano (urbes pequenas) amazônico, capitalista e segregador. Assim, partindo da teoria dos afetos de Spinoza (2013), "Ter saúde é estar apto a afetar e ser afetado por outros corpos em bons ou maus momentos. Sua contribuição mais importante é o deslocamento do político para o campo da ética e desta para o campo das emoçôes" (Sawaia, 2003, p. 92). Ou seja, sofrimentos ocasionados pela migração de povos Sateré-Maué e Hixcariana não podem ser reduzidos a algo individual ou apenas da mente. Estão ligados a suas vivências, a suas histórias, a suas cosmovisões e a suas coletividades.

O comum se torna uma força potencializadora de resistência ao sofrimento, de enfrentamento a investidas do Estado, do mercado e da forma como a urbe afeta os sujeitos. O comum favorece a "bons encontros" e conquistar espaços de vivência compartilhada da cidade. É possível entender "A saúde não como totalidade em si, nem uma relação imediata com a doença ou um estado definido biologicamente. Ela é a possibilidade de ter esperança e potencializar esta esperança em ação" (Sawaia, 2003, p. 93). Porquanto, olhar isso é também olhar para a qualidade dos encontros que a sociedade lhes permite desfrutar, para atravessamentos sociais vividos por indivíduos que, nesse caso, além da cidade, também vivenciam memórias de uma história de violência e genocídio vinculada a sua terra primordial.

A violência empregada pelo branco lança os Sateré-Maué e Hixcariana a uma vida de pobreza e exclusão/inclusão social. O cenário afeta o corpo pelo discurso ideológico de branquitude, cientificismo e racionalismo; e a mente, reforço de comportamento. $\mathrm{O}$ ato de transitar em espaços urbanos e vivenciar tradições e crenças (mesmo no contexto urbano) deixa de fazer parte da composição da sociabilidade coletiva, pois se perde em efeito de isolamento e ocasiona maus encontros.

Compreender os povos originários e seus saberes é levar em conta a terra, o ethos, suas parentelas e suas metaformatividades animais, além de saberes 
mediados por tuxauas e curas operadas via estratégias xamanísticas, é entender que "andar com os pés descalços" é o bom encontro, o afeto alegre, o sorriso e o brilho no olho. Manoel de Barros (2010) diz que "Tão triste é a vida sem marca dos pés", ao que compreendemos essa infelicidade tal e qual uma desvinculação a afetos positivos e à comunalidade.

\section{O COMUM E OS POVOS ORIGINÁRIOS: PARA NÃO CONCLUIR}

Partindo de uma visão spinoziana que não dicotomiza corpo e mente, razão e emoção, e coloca os afetos como definidores da qualidade ética da vida em sociedade, entende-se que a migração está ligada à saúde mental, cosmologia e exploração por parte do Estado. Portanto trabalha do ponto de vista singular e social. Assim, na análise da "doença mental", é preciso diagnosticar a qualidade dos encontros vivenciados, visto que, a partir deles, conforme Spinoza (2013), sua conatus é expandida ou não. E por isso a importância do comum nessa temática. Supomos que encontros vividos por povos originários na cidade tendem a lançá-los em condiçôes de sofrimento ético-político, fruto da dialética inclusão/exclusão social e desigualdade social. Isso ocasiona a diminuição da conatus e, por conseguinte, afeta a saúde de povos autóctones, concorrendo para um status de reatividade.

Esses encontros são diferentes em TI, pois ali existem locais de potência, ancestralidade e cosmogonia, ou seja, locais memoriais ao comum. Já a cidade, capitalista, esfacela esse comum, reproduzindo individualismos, competiçôes e afetaçôes. Foi necessário considerar historicidade e territorialidade na análise, pois ambas podem se vincular a sofrimentos, seja no campo da saúde ou não. No contexto da urbe, para povos originários, o comum é uma forma de potência e de resistência, visto que é por ele que esses povos podem enfrentar vivências controversas. Com isso, promover bons encontros é também enfrentar desigualdades sociais existente nas cidades sob a ótica dos afetos.

As reflexões tiveram o objetivo de sugerir caminhos para uma práxis junto a povos originários que considerasse cosmovisões e imemorialidades, e tendo o comum como norte para a potência e o fortalecimento do sujeito diante das violências do Estado e do mercado. Nisso também se projeta a potência do encontro entre as áreas aqui apresentadas, Psicologia social e Antropologia, que juntas podem fortalecer a formação de um comum junto a esses povos.

Acreditamos que, de modo geral, no Baixo Amazonas, a migração, em si mesma, representou, desde sempre, um exercício dialógico. Ação há séculos 
praticada pelo viés nômade que caracteriza nações pré-colombianas amazônicas. Um fluxo positivo que foi construído por conta de trocas econômicas (redes de sementes) e de gramáticas de guerra (presentes deixados como espólio de conflitos) (Fausto, 2001). No contexto dos Sateré-Maué e dos Hixcariana, o suposto é similar, de modo que a entendemos (a migração) como um movimento saudável, constitutiva da dinâmica de trocas alimentares e da predação dos povos.

Migrações formavam atos de domínio ou arrimo proteico quando se tratavam de ações operadas segundo causas alimentares de rituais ou festejos, ou ainda movimentos que envolviam parentescos e comidarias. Já no âmbito de atos bélicos, constituíam valores xamânicos, ou seja, era ganhando confrontos e partindo para novas terras, de forma a aquinhoar-se das "coisas e das pessoas vencidas", que o fluxo migracional se concretizava. E não apenas fisicamente, mas metafisicamente, porque itens xamânicos compunham o trânsito das movimentações entre terras amazônicas. Portanto notamos ser claro o sentido histórico da migração, e ele parece mostrar-se bem diferente dos aportes da atualidade, concernentes a problemáticas brancas e de cunho político e econômico.

Consideramos, portanto, que a migração como sofrimento éticopolítico, tal como a tratamos, depende de um contexto contingencial para assim se consolidar. A política, a economia, o Estado e o mercado são, por exemplo, agenciamentos que concorrem para sofrimentos ético-políticos, os quais não são similares a sofrimentos originários da sociocultura étnica, distribuída em cosmologia, parentesco, compadrio, consanguinidade, hierarquia clânica e afinidade. 


\section{REFERÊNCIAS}

Albuquerque, R. \& Junqueira, C. (2017). Brincando de onça e de cutias entre os Sateré-Mawé. Manaus: Editora da UFAM.

Albuquerque, R., Ferreira, R. A. Schweickardt, J. C., \& Cordeiro, M. C. (2016, janeiro-junho). Casos de "roubo de sombra" em fronteiras interétnicas: sofrimento mental no Baixo Amazonas/AM, Amazônia Central. Revista Comunnicare, 16(1), 140-156.

Albuquerque, R., Trindade, D. C., Paiva, I. T. P., \& Vieira Filho, R. D. (2014). Pajelanças indígena e cabocla no Baixo Amazonas/AM e suas implicações a partir de questão histórica. Ponto Urbe, 15. Recuperado a partir de http:// journals.openedition. org/pontourbe/2411

Barreto, A., \& Boyer, J. P. (2003). O indio que vive em mim: itinerário de um psiquiatra brasileiro. São Paulo: Terceira Margem.

Barreto, J. P. (2013, 23 dezembro). Como se tornar um especialista no conhecimento Tukano. Amazônia Real. Recuperado a partir de https:// amazoniareal.com.br/como-se-tornar-um-especialista-do-conhecimentotukano/

Barros, M. (2010). Mansidão. In M. de Barros, Poesia completa. (p. 44). São Paulo: Leya.

Botton, A. (2005). Desejo de status. Rio de Janeiro: Rocco.

Busarello, F. R. (2017). "Minha cor não é branca, minha cor não é negra, minha cor é canela": análise da vivência urbana dos Xokleng/Laklänó na cidade loira de Blumenau/SC. (Dissertação de Mestrado). Pontifícia Universidade Católica de São Paulo, Faculdde de Psicologia, São Paulo.

Cedeplar. (1977). Sudam: migraçôes internas na Regiāo Norte: estudo de campo da Região de Marabá. Belo Horizonte: Cedeplar/UFMG.

Cicchetti, D., \& Cohen, D. (2006). Developmental psychopathology. New York: John Wiley and Sons.

Clastres, P. (2002). A sociedade contra o Estado. T. Santiago (Trad.). São Paulo: Cosac \& Naify.

Collins, F. (2004). The case for a US prospective cohort study of genes and environment. Nature, 429(6990), 475-477. 
Comte-Sponville, A. (2001). A felicidade, desesperadamente. E. Brandão (Trad.). São Paulo: Martins Fontes.

Constituição da República Federativa do Brasil (1998). (1988). Brasília: Portal da Legislação.

Costello, J., Compton, S., Keeler, G., \& Angold, A. (2003, October). Relationships between poverty and psychopathology: a natural experiment. $J A M A, 290$ (15), 2023-2029. Recuperado a partir de https://jamanetwork. com/journals/jama/article-abstract/197482

Dantas, S. D. (2012). Para uma compreensão intercultural da realidade. In S. D. Dantas (Org.), Diálogos interculturais: reflexões interdisciplinares e intervençôes psicossociais. (pp. 15-23). São Paulo: Instituto de Estudos Avançados da Universidade de São Paulo.

Derrida, J. (2004). Gramatologia. São Paulo: Perspectiva.

Fausto, C. (2001). Inimigos fiéis: história, guerra e xamanismo na Amazônia. São Paulo: Edusp.

Garnelo, L., Diniz, L., Sampaio, S., \& Silva, A. (2010). Ambiente, saúde e estratégias de territorialização entre os índios Baniwa do Alto Rio Negro. Tellus, 18, 39-63.

Garnelo, L., \&Wright, R. (2001). Doença, cura e serviços de saúde: representaçôes, práticas e demandas Baniwa. Cadernos de Saúde Pública, 17(2), 273-284.

Jaspers, K. (1993). Psicopatologia geral. Rio de Janeiro: Atheneu.

José, E. N. S. (2015). Do encontro com o Outro para a Psicologia Cultural: a hermenêutica diatópica como referência no diálogo intercultural sobre a loucura. Manaus: Editora UFAM.

Kelly, J. A. (2005). Notas para uma teoria do "virar branco". Mana, 11(1), 201234.

Kirmayer, L. (2009). Cérebros, corpos e pessoas em movimento: a nova psiquiatria cultural e as ironias da globalização. In E. Lechner (Org.), Migração, saúde e diversidade cultural. (pp. 63-83). Lisboa: Imprensa de Ciências Sociais.

Klein, H. (2000). Migração internacional na história das Américas. In B. Fausto (Org.), Fazer a América. (pp. 13-32). São Paulo: Edusp. 
Lei no 6.001, de 19 de dezembro de 1973. (1973, 19 dezembro). Dispõe sobre o Estatuto do Índio. Brasília: Portal da Legislação. Recuperado a partir de http:// www.planalto.gov.br/ccivil_03/Leis/L6001.htm

Martine, G. (1987, julho-setembro). Migração e metropolização. São Paulo em Perspectiva, 1(2), 28-31.

Pereira, N. (2003). Os indios Maués. (2a ed.). Manaus: Valer e Governo do Estado do Amazonas.

Pusseti, C. (2009). Psicologias indígenas: da antropologia das emoções à etnopsiquiatria. In E. Lechner (Org.), Migração, saúde e diversidade cultural. (pp. 85-119). Lisboa: Imprensa de Ciências Sociais.

Rodrigues, R., Paiva, I., \& Catalão Júnior, A. (2012). A prática construtiva de um projeto político-pedagógico junto a índios Sateré-Mawé, na Amazônia Central. Muitas Vozes, 1, 271-285.

Rutter, M., \& Sroufe, A. (2000). Developmental psychopathology: concepts and challenges. Development and Psychopathol, 12(3), 265-296.

Santos, B. S., \& Nunes, J. A.(2003). Introdução: para ampliar o cânone do reconhecimento, da diferença e da igualdade. In B. S. Santos (Org.), Reconhecer para libertar: os caminhos do cosmopolitismo multicultural. (pp. 25-68). Rio de Janeiro: Civilização Brasileira.

Santos, J. (2013). Boi Campineiro: a história do Festival de Parintins que não foi contada. Manaus: Governo do Estado do Amazonas, Secretaria de Estado de Cultura.

Santos, R. V., \& Coimbra Júnior, C. E. A. (2003). Cenários e tendências da saúde e da epidemiologia dos povos indígenas no Brasil. In C. E. A. Coimbra Júnior, \& E. A. Carlos (Org.), Epidemiologia e saúde dos povos indígenas no Brasil. (pp. 13-47). Rio de Janeiro: Fiocruz/Abrasco.

Sarriera, J., Pizzinato, A., \& Meneses, M. (2005). Aspectos psicossociais da imigração na grande Porto Alegre. Estudos de Psicologia, 10, 5-14.

Sawaia, B. B. (1995). O calor do lugar: segregação urbana e identidade. São Paulo em Perspectiva, 9(2), 20-24.

Sawaia, B. B. (1999). Comunidade como ética e estética da existência: uma reflexão mediada pelo conceito de identidade. Psyque, 8(1), 19-25. 
Sawaia, B. B. (2003). O sentido ético-político da saúde na era do triunfo da tecnobiologia e do relativismo. In P. Goldenberg, R. Marsiglia, \& M. Gomes. (Org.), O clássico e o novo: tendências, objetos e abordagens em Ciências Sociais e Saúde. (pp. 83-96). Rio de Janeiro: Fiocruz.

Sawaia, B. B. (2008). O ofício da psicologia social à luz da ideia reguladora de sujeito: da eficácia da ação à estética da existência. In A. V. Zanella et al. (Org.), Psicologia e práticas sociais. (pp. 67-79). Rio de Janeiro: Centro Edelstein de Pesquisas Sociais.

Sawaia, B. B. (2009). Psicologia e desigualdade social: uma reflexão sobre liberdade e tranformação social. Psicologia \& Sociedade, 21(3), 364-372. Recuperado a partir de https://dx.doi.org/10.1590/S0102-71822009000300010

Sawaia, B. B. (Org.) (2001). As artimanhas da exclusão: análise psicossocial e ética da desigualdade social. (2a ed.). Petrópolis: Vozes.

Sawaia, B. B., \& Silva, D. N. H. (2015, outubro). Pelo reencantamento da Psicologia: em busca da positividade epistemológica da imaginação e da emoção no desenvolvimento humano. Caderno Cedes, 35(num. esp.), 343-360.

Spinoza, B. (2013). Ética. (2a ed.). Belo Horizonte: Autêntica.

Spinoza, B. (2014). Obra completa I: (Breve) tratado e outros escritos. J. Guinsburg, N. Cunha, R. Romano (Ed.). São Paulo: Perspectiva.

Teixeira, P., Mainbourg, E., \& Brasil, M. (2009). Migração do povo indígena Sateré-Mawé em dois contextos urbanos distintos na Amazônia. Caderno CRH, 22(57), 531-546. 